\title{
Children Exposed to Treatments in Utero in Pregnant Patients with Breast Cancer: Experience from Two Large Egyptian Hospitals
}

\author{
Soha M. Talima ${ }^{1}$, Moustafa Al Daly ${ }^{1}$, Mohammed Hammam ${ }^{2}$, Ahmed Bader ${ }^{3}$ \\ ${ }^{1}$ Kasr Al-Ainy Center of Clinical Oncology \& Nuclear Medicine, Faculty of Medicine, Cairo University, \\ Cairo, Egypt; ${ }^{2}$ Department of Obstetrics and Gynecology, Faculty of Medicine, Cairo University, Cairo, \\ Egypt; ${ }^{3}$ Department of Pediatrics, Faculty of Medicine, Cairo University, Cairo, Egypt
}

Background: Pregnancy-associated breast cancer (PABC) is one of the common malignancies during pregnancy. Limited data is present about the effect of anticancer therapy on children born to mothers exposed to in utero treatments.

Aim: To describe the outcome of pregnancy in a cohort of Egyptian patients treated for PABC.

Methods: We reviewed all breast cancer cases diagnosed during pregnancy at two large Egyptian institutions between January 2009 and December 2016. Thirty-eight patients with complete obstetric and fetal data were included. Results: All patients received anthracycline-based chemotherapy in the $2^{\text {nd }}$ and $3^{\text {rd }}$ trimesters and 9 of them received paclitaxel. The mean gestational age at delivery was $35.7 \pm 3.4$ weeks. The mean birth weight was $2736 \pm 768$ grams Congenital anomaly (cleft lip and tongue tie) was reported in only one (4\%) child. Perinatal death occurred in one (4\%) baby due to prematurity. One $(4 \%)$ child was exposed to trastuzumab in utero in the $1^{\text {st }}$ trimester and he was completely healthy. Two (8\%) other children were exposed to tamoxifen with no complications either neonatal or postnatal. Conclusion: Chemotherapy during pregnancy may be used with minimal maternal and fetal complications. Multidisciplinary approach is crucial for better management. Continued long-term follow-up of the children in this cohort is required.

Keywords: Chemotherapy, Neonatal outcome, Pregnancy associated breast cancer

Corresponding author: Soha Talima, MD; Clinical Oncology department, Kasr Al-Ainy Center of Clinical Oncology and Nuclear Medicine (NEMROCK), Kasr Al-Ainy School of Medicine, Cairo University; Email: soha_talima@ hotmail.com Submitted: 18-March-2018, Revised: 9-May-2018, Accepted: 30-May-2018, Published online: 2-August-2018

\section{INTRODUCTION}

Pregnancy-associated breast cancer $(\mathrm{PABC})$ is defined as breast cancer occurring during pregnancy or in the $1^{\text {st }}$ year postpartum. It is the commonest form of invasive cancer in pregnant women ${ }^{\mathbf{1 - 4}}$. It makes up about $7 \%$ of all breast cancers in women $<45$ years of age in western nations with the incidence expected to rise due to women's delay in childbearing ${ }^{5,6}$.

$\mathrm{PABC}$ has a clinic-biological picture characterized by presenting commonly at a younger age in an advanced-stage with aggressive biology associated with higher tumor grades, less expression of estrogen and progesterone receptors and more expression of Her2 receptor. These may be associated with poor prognosis as reported in multiple large retrospective studies ${ }^{2,7}$. However, some studies didn't find worse prognosis after adjustment for age and tumor characteristics ${ }^{5,8,9}$.

The optimal management of PABC is not established well; careful diagnosis, staging, and therapeutic interventions within a multidisciplinary approach is needed for the proper balance of benefits and hazards for the mother and her fetus.

Chemotherapy is often required in most cases presenting with advanced-stage and/or aggressive biology. There is growing evidence that the administration of chemotherapy during pregnancy is probably safe. Data from long-term follow-up (up to 19 years) indicates only minimal deleterious effects on the fetus except for prematurity ${ }^{10}$. However, chemotherapy administration during the $1^{\text {st }}$ trimester must be avoided due to the high risk of teratogenicity that may occur during this period of organogenesis (5-12 weeks) ${ }^{11}$. Furthermore, the possibility of spontaneous abortion or fetal malformations ranges from $10-20 \%$ with chemotherapy administrated during that period ${ }^{12-14}$. Current standard chemotherapeutic agents that can be used in the adjuvant or neoadjuvant settings include an anthracycline, which is considered safer than alkylating agents such as cyclophosphamide ${ }^{15}$. The teratogenicity of fluorouracil remains unclear ${ }^{16}$. About taxanes, data is accumulating regarding its safety for use during pregnancy ${ }^{17}$.

Trastuzumab is considered a standard-of-care in the treatment of HER2-positive breast cancer, either in the adjuvant or advanced-disease setting, as it reduces the risk of relapse and improves overall survival ${ }^{18-22}$. The administration of trastuzumab in pregnant patients is reported to be associated with a high incidence of oligoand/or anhydramnios as well as renal failure associated with poor neonatal outcome. That is why it is not recommended during pregnancy ${ }^{23}$.

Hormonal treatments, like tamoxifen, should be postponed until delivery as they are associated with documented teratogenic effects ${ }^{24}$. 
Data confirming the safety of chemotherapy administration during pregnancy with no major maternal or fetal complications is accumulating. However, data of long-term outcomes of children exposed in utero to chemotherapy is still limited ${ }^{25}$.

The objective of this study was to describe the pregnancy outcome in a cohort of Egyptian patients who had been treated for breast cancer with systemic anticancer therapy during pregnancy.

\section{METHODS}

Between January 2009 and December 2016, 57 patients presented with PABC in the two Egyptian cancer centers participating in this study, the Kasr AlAiny Centre of Clinical Oncology and Nuclear Medicine (NEMROCK), Cairo University in Cairo and Aswan Cancer Center in Aswan. Data about the pregnancy and neonatal outcomes were obtained from the Department of Obstetrics and Gynecology and the Pediatric Neonatology Unit. The study was approved by the ethical committees of the two institutes. The following information was obtained from medical records: age of the patient at diagnosis, gestational age at diagnosis during which the patient received chemotherapy and any complications that occurred during pregnancy together with neonatal data as birth weight and any neonatal malformations.

Once the patient was diagnosed with breast cancer, consultation with the obstetrician within the multidisciplinary team was performed for careful assessment of the fetal health. The patient was informed about the potential side effects of chemotherapy on the fetus. Also, the limited data on long-term hazards to the infant was discussed carefully with the patient.

For operable disease, surgical consultation was obtained within the multidisciplinary team. Chemotherapy during pregnancy consisted of standard FAC (cyclophosphamide $500 \mathrm{mg} / \mathrm{m}^{2}$, adriamycin 50 $\mathrm{mg} / \mathrm{m}^{2}$ and 5 -fluorouracil $500 \mathrm{mg} / \mathrm{m}^{2}$ on day 1 ; repeated every 21 days), AC (adriamycin $60 \mathrm{mg} / \mathrm{m}^{2}$ and cyclophosphamide $500 \mathrm{mg} / \mathrm{m}^{2}$ on day 1 ; repeated every 21 days) or AC sequentially with paclitaxel $\left(80 \mathrm{mg} / \mathrm{m}^{2}\right)$.

The descriptive statistical analysis was performed using the Statistical Package for Social Sciences (SPSS) version 10.0 software program for Windows (SPSS, Chicago, IL).

\section{RESULTS}

The analysis included 38 PABC patients with adequate data in the oncology and obstetric departments. Thirty-eight children were born after exposure to varying numbers and types of anticancer treatments in utero.

Details of systemic anti-cancer treatment are illustrated in table 1 . All of our cohort of children were exposed to anthracycline-based chemotherapy with $76.3 \%(n=29)$ had exposure to at least four cycles. FAC regimen was the most commonly administered chemotherapy in pregnant patients $(n=21,55.3 \%)$. The remaining 17 patients were treated with $\mathrm{AC}$ regimen. Of the planned AC/paclitaxel treatment, more than 4 weeks of paclitaxel therapy was completed in 9 patients. Chemotherapy was given during the $2^{\text {nd }}$ trimester in 20 $(52.6 \%)$ patients and the $3^{\text {rd }}$ trimester in $18(47.4 \%)$.

Delivery data and neonatal complications are shown in table 2. Mean gestational age for babies after exposure to chemotherapy at delivery was $35.7 \pm 3.4$ weeks. Nine $(23.7 \%)$ of the patients had a premature delivery. Eighteen patients delivered by normal vaginal delivery and 16 patients by cesarean section. Four patients had no data about the mode of delivery. Data on the birth weight was available for 27 babies. The mean birth weight was $2736 \pm 768$ grams. Neonatal birth weight was $<10 \%$ for gestational age in 9 cases $(9 / 27,33.33 \%)$. It was noted that $77.7 \%$ of babies born with birth weight small for gestational age, occurred in mothers who received paclitaxel. Perinatal death occurred in one baby born prematurely.

Of the 38 babies born, data on the complications that occurred during and/or after delivery was present in 25 babies. The commonest complication that occurred in the neonatal period was neonatal jaundice ( 5 babies). Of the entire cohort, one child had a congenital anomaly in the form of a cleft lip and tongue tie. Another baby was born with undescended testis.

In our cohort of children, two were exposed to tamoxifen in utero. In the $1^{\text {st }}$ case, the mother became pregnant while on a 4-year adjuvant tamoxifen therapy. The patient delivered a healthy baby who is now 5 years old and has no congenital abnormalities or developmental problems. The $2^{\text {nd }}$ child was exposed

Table 1: Systemic anti-cancer treatment in 38 patients with pregnancy-associate breast cancer

\begin{tabular}{|c|c|c|}
\hline Systemic anti-cancer treatment & & n (\%) \\
\hline \multicolumn{3}{|l|}{ Chemotherapy } \\
\hline \multirow[t]{2}{*}{ Gestational age at time of chemotherapy } & $2^{\text {nd }}$ trimester & $20(52.6)$ \\
\hline & $3^{\text {rd }}$ trimester & $18(47.4)$ \\
\hline \multirow[t]{3}{*}{ Chemotherapy regimen } & FAC (5-fluorouracil, doxorubicin, and cyclophosphamide) & $21(55.3)$ \\
\hline & AC (Adriamycin and cyclophosphamide) & $8(21)$ \\
\hline & $\mathrm{AC}+$ paclitaxel & $9(23.7)$ \\
\hline \multirow[t]{2}{*}{ Number of cycles } & $>4$ cycles of anthracycline based chemotherapy & $29(76.3)$ \\
\hline & $\leq 3$ cycles of anthracycline based chemotherapy & $9(23.7)$ \\
\hline \multicolumn{3}{|l|}{ Hormonal therapy (tamoxifen) } \\
\hline Gestational age at time of tamoxifen & $1^{\text {st }}$ trimester & $2(5.2)$ \\
\hline \multicolumn{3}{|l|}{ Anti-her2 neu receptors (trastuzumab) } \\
\hline Gestational age at time of trastuzumab & $1^{\text {st }}$ trimester & $1(2.6)$ \\
\hline
\end{tabular}


Table 2: Neonatal outcome of children exposed in utero to systemic anti-cancer treatment for breast cancer

\begin{tabular}{|c|c|c|c|}
\hline & All & FAC / AC & $\mathrm{AC}+$ paclitaxel \\
\hline & $\mathrm{n}(\%)$ & $\mathrm{n}(\%)$ & $\mathrm{n}(\%)$ \\
\hline \multicolumn{4}{|l|}{ Gestational age at delivery $(n=38)$} \\
\hline Preterm $(<37$ weeks $)$ & $9(23.7)$ & $4(44.4)$ & $5(55.6)$ \\
\hline Term $(\geq 37$ weeks $)$ & $29(76.4)$ & $25(86.2)$ & $4(13.8)$ \\
\hline \multicolumn{4}{|l|}{ Mode of delivery $(n=34)$} \\
\hline Normal Vaginal delivery & $18(52.9)$ & $14(77.7)$ & $4(22.3)$ \\
\hline Caesarean section & $16(47.1)$ & $11(68.7)$ & $5(31.3)$ \\
\hline \multicolumn{4}{|l|}{ Birth weight for gestational age $(n=27)$} \\
\hline Appropriate & $18(66.66)$ & $16(88.9)$ & $2(11.1)$ \\
\hline Small for gestational age ( $<10$ th percentile) & $9 \quad(33.33)$ & $2(22.3)$ & $7(77.7)$ \\
\hline \multicolumn{4}{|l|}{ Fetal complications $(n=25)$} \\
\hline Jaundice & $5(20)$ & $2(40)$ & $3(60)$ \\
\hline Neonatal ICU hospitalization $(n=15)$ & $1(6.7)$ & $1(100)$ & 0 \\
\hline Congenital anomaly & $1(4)$ & $1(100)$ & 0 \\
\hline Undescended testis & $1(4)$ & $1(100)$ & 0 \\
\hline Intrauterine fetal demise & 0 & 0 & 0 \\
\hline Neonatal death & $1(4)$ & $1(100)$ & 0 \\
\hline
\end{tabular}

FAC: 5-fluorouracil, doxorubicin, and cyclophosphamide; AC: Adriamycin and cyclophosphamide

to 2 months of tamoxifen and he is in complete health.

Another child was born to a mother exposed to trastuzumab in utero. The patient received 4 cycles of trastuzumab. Despite having an intrauterine device, she became pregnant without knowing and completed 4 cycles of trastuzumab before the discovery of her pregnancy. The child born was completely normal and healthy. He is now 3 years old.

\section{DISCUSSION}

In this multi-institutional, retrospective study involving 38 children exposed to in utero anticancer treatments, we documented the possible safety of chemotherapy administration including anthracyclines and taxane during pregnancy without significant adverse fetal or postnatal outcomes.

The main neonatal problem observed in our study was low birth weight, the incidence of which was $33.3 \%$. This percent is higher than that in the general population of the United States which is $12.2 \%{ }^{26}$.

One $(4 \%)$ of the children in our series was born with a congenital anomaly (cleft palate). The rate of congenital abnormalities in our cohort is little bit higher than the United States average rate of approximately 3\% 27. Exposure to cytotoxic drugs during the $1^{\text {st }} 12$ weeks of pregnancy may result in spontaneous abortions and increase the risk of birth defects ${ }^{11}$. On the other hand, the safe use of certain chemotherapeutics in the $2^{\text {nd }}$ and $3^{\text {rd }}$ trimesters is confirmed in multiple studies ${ }^{28-30}$.

Our data is comparable to a prospective clinical trial by Hahn et al, who reported the short-term safety of FAC chemotherapy given during the $2^{\text {nd }}$ and/or $3^{\text {rd }}$ trimesters in PABC ${ }^{31}$. Follow-up with the same children (median age of 7 years) was reported by Murthy et al. They found that the majority of the children were healthy with no significant complications observed related to chemotherapy exposure. Congenital abnormalities were reported in 3 cases in that study ${ }^{32}$.

In another study conducted by Amant et al, prenatal exposure to chemotherapy was not associated with increased complications. They did not find an association between prenatal exposure to chemotherapy and central nervous system, cardiac or auditory toxicities 10 .

Anthracyclines based chemotherapy regimens (AC or FAC) are the most commonly used chemotherapy regimens in $\mathrm{PABC}{ }^{33}$. As for taxanes, despite their integral role in the treatment of breast cancer, limited data is present on their use during pregnancy ${ }^{34}$. In our series, about $23 \%$ of PABC patients who received AC also received one or more cycles of weekly paclitaxel with no observed undesirable effects. We observed higher incidence $(77.7 \%)$ of low birth weight babies born to mothers received weekly paclitaxel compared to FAC chemotherapy.

Trastuzumab administration is contraindicated for $\mathrm{PABC}$ as it may result in serious complications as oligohydramnios and renal failure. However, some reported that in utero exposure to trastuzumab during the $1^{\text {st }}$ trimester was followed by the delivery of healthy babies without congenital malformations ${ }^{35}$. Fortunately, adjuvant regimens containing trastuzumab for the treatment of her2 positive disease start with anthracyclines based chemotherapy, so give the time for a pregnant patient to give birth before starting trastuzumab. The start of treatment can be delayed until completion of pregnancy without adversely affecting the survival outcomes ${ }^{36}$. In our series, one child was exposed during $1^{\text {st }}$ trimester to 4 cycles of trastuzumab without neonatal or postnatal adverse effects.

The use of tamoxifen is known to be teratogenic. Some case reports indicated healthy babies born after exposure to tamoxifen 24,37 . In contrast, a study by Braems et al, reported a higher incidence of congenital malformations after in utero exposure to tamoxifen as reported by the AstraZeneca Safety Database. Eleven babies were born with congenital malformations out of 44 live births, which means that every four live births, one infant was born with malformations ${ }^{38}$. We report 2 children born to patients who became pregnant while taking tamoxifen therapy. The $1^{\text {st }}$ child is now 4 years old and completely healthy with no abnormalities. The 
$2^{\text {nd }}$ baby is now 4 months and he is a normal healthy baby.

This study was limited by its small sample size and short follow-up period. More prolonged follow up is needed to determine the effect of extensive in utero chemotherapy exposure on health outcomes of the children.

In conclusion, anthracycline-based chemotherapy \pm paclitaxel may be used for PABC without major maternal or fetal complications. Follow-up of these children is needed to assess any future problems especially when they become adults.

\section{Acknowledgement}

This study was a continuation of Abdelrahman et al ${ }^{25}$ report on the initial outcome of children born after exposure to in utero chemotherapy.

\section{Conflict of interest}

The authors have no conflict of interest to declare.

\section{REFERENCES}

1. Andersson TM, Johansson AL, Hsieh CC, Cnattingius S, Lambe M. Increasing incidence of pregnancy-associated breast cancer in Sweden. Obstet Gynecol. 2009; 114(3): 568-572.

2. Stensheim H, Møller B, van Dijk T, Fossa SD. Causespecific survival for women diagnosed with cancer during pregnancy or lactation: a registry-based cohort study. J Clin Oncol. 2009; 27(1): 45-51.

3. Lethaby AE, O'Neill MA, Mason BH, Holdaway IM, Harvey VJ. Overall survival from breast cancer in women pregnant or lactating at or after diagnosis. Auckland Breast Cancer Study Group. Int J Cancer. 1996; 67(6): 751-755.

4. Beadle BM, Woodward WA, Middleton LP, et al. The impact of pregnancy on breast cancer outcomes in women <or=35 years. Cancer. $2009 ; 115(6)$ : 1174-1184.

5. Abenhaim HA, Azoulay L, Holcroft CA, Bure LA, Assayag J, Benjamin A. Incidence, risk factors, and obstetrical outcomes of women with breast cancer in pregnancy. Breast J. 2012; 18(6): 564-568.

6. Smith LH, Danielsen B, Allen ME, Cress R. Cancer associated with obstetric delivery: results of linkage with the California cancer registry. Am J Obstet Gynecol. 2003; 189(4): 1128-1135.

7. Guinee VF, Olsson H, Moller T, et al. Effect of pregnancy on prognosis for young women with breast cancer. Lancet. 1994; 343(8913): 1587-1589.

8. Murphy CG, Mallam D, Stein S, et al. Current or recent pregnancy is associated with adverse pathologic features but not impaired survival in early breast cancer. Cancer. 2012; 118(13): 3254-3259.

9. Mathelin C, Annane K, Treisser A, et al. Pregnancy and post-partum breast cancer: a prospective study. Anticancer Res. 2008; 28(4C): 2447-2452.

10. Amant F, Van Calsteren K, Halaska MJ, et al. Long-term cognitive and cardiac outcomes after prenatal exposure to chemotherapy in children aged 18 months or older: an observational study. Lancet Oncol. 2012; 13(3): 256-264.

11. Cardonick E, Iacobucci A. Use of chemotherapy during human pregnancy. Lancet Oncol. 2004; 5(5): 283-291.

12. Eedarapalli P, Jain S. Breast cancer in pregnancy. J Obstet Gynecol. 2006; 26(1):1-4.
13. Espie M, Cuvier C. Treating breast cancer during pregnancy. What can be taken safely? Drug Saf. 1998; 18(2):135-142.

14. Lenhard MS, Bauerfeind I, Untch M. Breast cancer and pregnancy: challenges of chemotherapy. Crit Rev Oncol Hematol. 2008; 67(3): 196-203.

15. Turchi J, Villasis C. Anthracyclines in the treatment of malignancy in pregnancy. Cancer. 1988; 61(3):435-440.

16. Stephens JD, Golbus MS, Miller TR, Wilber RR, Epstein CJ. Multiple congenital anomalies in a fetus exposed to 5 fluorouracil during the first trimester. AmJ Obstet Gynecol. 1980; 137(6):747-749.

17. Zagouri F, Sergentanis TN, Chrysikos D, et al. Taxanes for Breast Cancer During Pregnancy: A Systematic Review. Clin Breast Cancer. 2013; 13(1): 16-23.

18. Piccart-Gebhart MJ, Procter M, Leyland-Jones B, et al. Trastuzumab after adjuvant chemotherapy in HER2positive breast cancer. N Engl J Med. 2005; 353(16): 1659-1672.

19. Untch M, Fasching PA, Konecny GE, et al. Pathologic complete response after neoadjuvant chemotherapy plus trastuzumab predicts favorable survival in human epidermal growth factor receptor 2-overexpressing breast cancer: results from the TECHNO trial of the AGO and GBG study groups. J Clin Oncol. 2011; 29(25): 33513357.

20. Gianni L, Dafni U, Gelber RD, et al. Treatment with trastuzumab for 1 year after adjuvant chemotherapy in patients with HER2-positive early breast cancer: a 4-year follow-up of a randomized controlled trial. Lancet Oncol. 2011; 12(3): 236-244.

21. Valero V, Forbes J, Pegram MD, et al. Multicenter phase III randomized trial comparing docetaxel and trastuzumab with docetaxel, carboplatin, and trastuzumab as first-line chemotherapy for patients with HER2-gene-amplified metastatic breast cancer (BCIRG 007 study): two highly active therapeutic regimens. J Clin Oncol. 2011; 29(2): 149-156.

22. Andersson M, Lidbrink E, Bjerre K, et al. Phase III randomized study comparing docetaxel plus trastuzumab with vinorelbine plus trastuzumab as first-line therapy of metastatic or locally advanced human epidermal growth factor receptor 2-positive breast cancer: the HERNATA study. J Clin Oncol, 2011; 29(3):264-271.

23. Córdoba O, Llurba E, Saura C, et al. Multidisciplinary approach to breast cancer diagnosed during pregnancy: maternal and neonatal outcomes. Breast. 2013; 22(4): $515-519$.

24. Isaacs RJ, Hunter W, Clark K. Tamoxifen as systemic treatment of advanced breast cancer during pregnancy -case report and literature review. Gynecol Oncol. 2001; 80(3): 405-408

25. Abdelrahman M, Hammam M, Bader A, Omar OS. Is it safe to treat Breast Cancer during Pregnancy? - A single institution five years retrospective experience. Pan Arab J Oncol. 2014; 7(3): 22-26.

26. Martin JA, Hamilton BE, Ventura SJ, et al. Births: final data for 2009. Natl Vital Stat Rep. 2011; 60(1): 1-70.

27. Centers for Disease Control and Prevention, National Center for Health Statistics: Birth Defects: Data \& Statistics. (http://www.cdc.gov/ncbddd/ birthdefects/data.html)

28. Loibl S, von Minckwitz G, Gwyn K, et al. Breast carcinoma during pregnancy. International recommendations from an expert meeting. Cancer. 2006; 106(2): 237-246.

29. Peccatori FA, Azim Jr HA, Scarfone G, et al. Weekly epirubicin in the treatment of gestational breast cancer (GBC). Breast Cancer Res Treat. 2009; 115(3):591-594. 
30. Amant F, Deckers S, Van Calsteren K, et al. Breast cancer in pregnancy: Recommendations of an international consensus meeting. Eur J Cancer. 2010; 46(18): 31583168.

31. Hahn KM, Johnson PH, Gordon N, et al. Treatment of pregnant breast cancer patients and outcomes of children exposed to chemotherapy in utero. Cancer. 2006; 107(6): $1219-1226$.

32. Murthy RK, Theriault RL, Barnett CM, et al. Outcomes of children exposed in utero to chemotherapy for breast cancer. Breast Cancer Res. 2014; 16(6): 500.

33. Berry DL, Theriault RL, Holmes FA, et al. Management of breast cancer during pregnancy using a standardized protocol. J Clin Oncol. 1999; 7(3):855-861.

34. Mir O, Berveiller P, Goffinet F, et al. Taxanes for breast cancer during pregnancy: a systematic review. Ann Oncol. 2010; 21(2): 425-426.
35. Zagouri F, Sergentanis TN, Chrysikos D, Papadimitriou CA, Dimopoulos MA, Bartsch R. Trastuzumab administration during pregnancy: a systematic review and meta-analysis. Breast Cancer Res Treat. 2013; 137(2): 349-357.

36. Gottschalk I, Berg C, Harbeck N, Stressig R, Kozlowski P. Fetal renal insufficiency following trastuzumab treatment for breast cancer in pregnancy: case report und review of the current literature. Breast Care (Basel). 2011; 6(6):475-478.

37. Oksuzoglu B, Guler N. An infertile patient with breast cancer who delivered a healthy child under adjuvant tamoxifen therapy. Eur J Obstet Gynecol Reprod Biol. 2002; 104(1):79.

38. Braems G, Denys H, De Wever O, Cocquyt V, Van den Broecke R. Use of tamoxifen before and during pregnancy. Oncologist. 2011; 16(11): 1547-1551. 